\title{
The integrative density model of the crust and upper mantle of Eurasia: representation in GIS environment
}

\author{
Mikhail K. Kaban ${ }^{1,2,3}$, Roman I. Krasnoperov ${ }^{2}$, Anatoly A. Soloviev ${ }^{2,3}$, and Yulia I. Nikolova ${ }^{2}$
}

Received 6 November 2019; accepted 6 November 2019; published 30 November 2019.

Modern geoinformation systems (GIS) are an indispensable instrument for efficient management of geographically referenced Earth sciences data. The Geophysical Center of the Russian Academy of Sciences (GC RAS) has a vast experience of development of web-oriented multidisciplinary GIS for geological and geophysical data representation and comprehensive analysis. One of the major segments of the geodatabase of GC RAS is geophysical and geological data on the solid Earth. This includes data on global gravity models, rheological parameters of the lithosphere, Moho depths, dynamic topography etc. As a case study for this paper an integrative density model of the crust and upper mantle of Eurasia was considered. It was compiled by the scientific team of the German Research Center for Geosciences (GFZ) using large sets of available seismic and gravity field data. This paper gives a detailed description of the model's construction process. For representation of this model in GIS environment it was converted into a GIS-compatible series of the data layers. To facilitate the wide access to this data, they were published in the form of an online map-service. KEYWORDS: Earth crust; upper mantle; density heterogeneity; integrative density model; residual gravity; residual topography; geoinformation system; geodatabase; online map-services.

Citation: Kaban, Mikhail K., Roman I. Krasnoperov, Anatoly A. Soloviev, and Yulia I. Nikolova (2019), The integrative density model of the crust and upper mantle of Eurasia: representation in GIS environment, Russ. J. Earth. Sci., 19, ES6004, doi:10.2205/2019ES000692.

\section{Introduction}

The continuous growth of geological and geophysical data on structure and evolution of the Earth's physical layers requires adequate methods for their storage, processing, analysis and representation. Currently, this problem is becoming quite topical among the experts in the field of data sci-

\footnotetext{
${ }^{1}$ German Research Center for Geosciences (GFZ), Potsdam, Germany

${ }^{2}$ Geophysical Center RAS, Moscow, Russia

${ }^{3}$ Schmidt Institute of Physics of the Earth RAS, Moscow, Russia
}

Copyright 2019 by the Geophysical Center RAS. http://rjes.wdcb.ru/doi/2019ES000692-res.html ence and interdisciplinary interaction. Recent advances in geoinformatics and systems analysis allow us to find a solution to this problem. Modern geographic information systems (GIS) are one of the main tools for geospatial data management that demonstrate adequate versatility. At the same time, modern trends in data science, including the so-called "Big Data" concept, are also taken into account [Science..., 2015].

Currently, a number of specialized GIS services have been created and are successfully functioning for solving the outlined problems. Despite their diversity in the field of geophysics, there is an evident lack of efficient solution that combines multidisciplinary geological and geophysical data and provides a wide range of tools for their analysis 
and representation, using modern geoinformation and network technologies. Existing GIS that provide the necessary functionality, as a rule, are implemented as user desktop software (e.g. ArcGIS, MapInfo, gvSIG, etc.) or web-services provided on a commercial basis [Fu, 2016. This paper gives a brief outlook of the research that's being carried out in cooperation between the Geophysical Center of the Russian Academy of Sciences (GC RAS) and German Research Centre for Geosciences (GFZ). The research is devoted to development of the web-oriented GIS that integrates a large variety of geospatial data on Earth's sciences along with processing tools and analytical instruments in geoinformation environment. Such a GIS is based on the approach that has certain advantages: open network access to the geodatabase and processing tools on the server side; access to large arrays of geodata that are difficult to transfer across the network and process on the client side because of their significant volumes [Beriozko et al., 2009, 2011, Krasnoperov and Soloviev, 2015. Krasnoperov et al., 2016; Soloviev et al., 2016,2018.

Geospatial data on the internal structure of the lithosphere and mantle are presented in the form of raster and vector GIS layers, centrally stored in a single geodatabase. In particular, the created geodatabase includes data-layers that are based on a number of modern models of the gravity field of the Earth e.g. EIGEN-6C [Shako et al., 2013], compiled on the basis of geophysical satellite data (LAGEOS, CHAMP, GOCE, GRACE etc.), as well as the results of ground-based measurements. The procedure of construction of the density model of the crust and upper mantle is given in this paper.

\section{Density Model of the Crust and Upper Mantle of Eurasia: Motivation}

Mass anomalies in the Earth's mantle associated with thermal or compositional heterogeneities are one of the main factors initiating mantle convection, plumes, subduction, and deformation of the lithosphere. Therefore, knowledge of the density heterogeneity of the upper mantle is a key for understanding of tectonic processes. This is particularly important in Eurasia, where nearly all types of tectonic settings are present. Up to now, seismic tomography remains a major tool for studying of the mantle properties. However, seismic ve- locities provided by various tomography methods don't allow to obtain a complete image of the upper mantle, e.g. [Kaban et al., 2016a]. They are mostly sensitive to temperature variation and content of volatiles and to a less extent to compositional changes e.g. [Goes, 2000; Stixrude, 2005. For example, eclogites, which can be present in the upper mantle, are characterized by seismic velocities similar to peridotites forming the normal upper mantle, while the first ones are much denser in the same P-T conditions e.g. [Anderson, 1984]. On the other hand, the depleted upper mantle in the cratonic roots is less dense in the same $\mathrm{P}$-T conditions then the normal continental upper mantle, while is characterized by nearly the same seismic velocities e.g. [Jordan, 1978]. Gravity field is sensitive to both, thermal and compositional anomalies, however its interpretation represents an ill-posed and highly non-unique problem [Kaban, 2011]. Therefore, no single method can be used to create a comprehensive model of the upper mantle. In the series of papers, which are summarized here, an integrative analysis of various data constrained by mineral physics equations is employed to create a 3D density model of the upper mantle of Eurasia and to determine the impact of temperature and compositional changes on the density variations [Kaban et al., 2010, 2016a, Stolk et al., 2013. Tesauro et al., 2008, 2009]. The created model provided geospatial data for compilation of the GIScompatible data-layers. Furthermore the technique of the model's construction is reviewed.

\section{Model of the Crust}

One of the principal issues of upper mantle density modelling is the elimination of the crustal effect from the observed gravity field. The crust is the most heterogeneous layer in the Earth, and its gravitational signal completely masks the signals of other layers, including the upper mantle, $[\mathrm{Ka}$ ban et al., 2016a. The only way to overcome this principal issue is construction of a $3 \mathrm{D}$ model of the crust, which is based on available seismic data providing direct determination of the crustal properties (thickness of the crustal layers and variations of seismic velocities within them). The seismic velocities can be converted to density variations since for the crystalline crust this conversion is relatively straightforward [Christensen and Mooney, 1995]. 


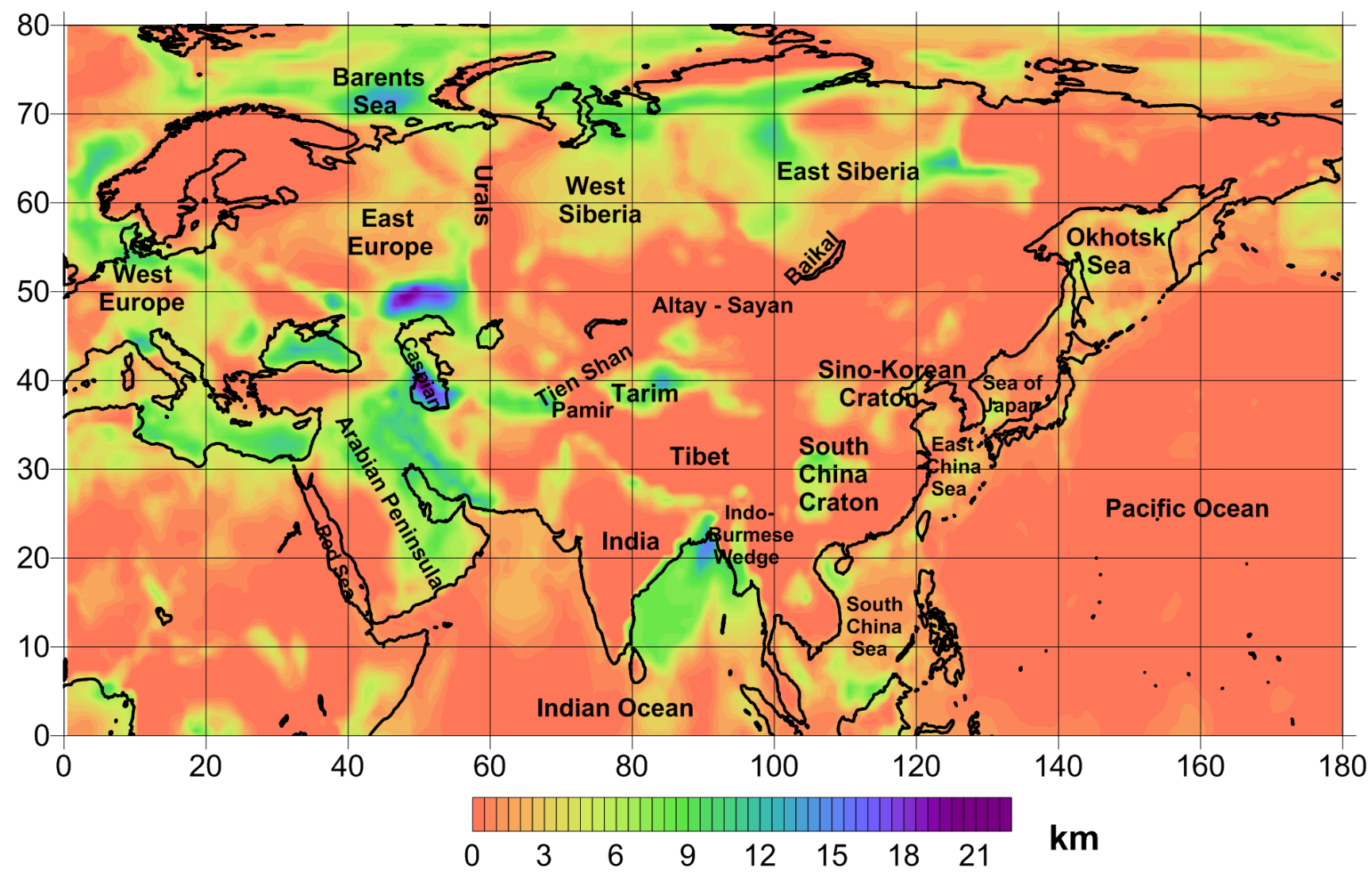

Figure 1. Thickness of the sedimentary layer.

This model can be used then to determine the gravity effect of the crust and to remove it from the observed gravity field.

The area, which is considered in these studies, includes most of Eurasia within the frames $0^{\circ}-80^{\circ} \mathrm{N}$ and $0^{\circ}-180^{\circ} \mathrm{E}$. The model of the crust was constructed by Tesauro et al. 2008 and Stolk et al. 2013 for Europe and Asia correspondingly. These models provide thicknesses of sediments and layers of the crystalline crust. Each crustal layer is characterized by variations in $\mathrm{P}$-wave velocity $\left(V_{p}\right)$, which have been converted into density variations using the experimental non-linear relationships of Christensen and Mooney 1995.

Over the continent area, the sedimentary thickness variations were chiefly compiled from detailed regional maps based on geophysical and geological studies [Stolk et al., 2013. Tesauro et al., 2008], which are supplemented by data from the Exxon Tectonic Map of the World 1985 in the areas, where regional maps are not available. Offshore, the detailed model constructed by the National Oceanic and Atmospheric Administration (NOAA) [Divins, 2003 has been employed. In addition, new data for the Middle East region have been implemented according to [Kaban et al., 2016b]. All the data are presented on the same $1^{\circ} \times 1^{\circ}$ grids related to geographical coordinates. The obtained distribution of the sediments thickness is demonstrated in Figure 1. For each sedimentary basin specific velocity- and density-depth relationships were determined, which are based on available geophysical and geological data [Stolk et al., 2013. Tesauro et al., 2008.

The model of the crystalline crust of Eurasia is based on the database prepared in the US Geological Survey [Mooney, 2007], with updates up to 2015. A new methodology has been used for mapping of the Moho discontinuity in areas with heterogeneously distributed seismic data on the Moho depth.

The Moho determinations have been interpolated by employing the so-called remove-computerestore technique [Stolk et al., 2013], which has been previously used in geodesy applications e.g. [Forsberg and Tscherning, 1997]. According to this approach, the observations were initially corrected for Airy-type isostasy. The obtained "residual" 


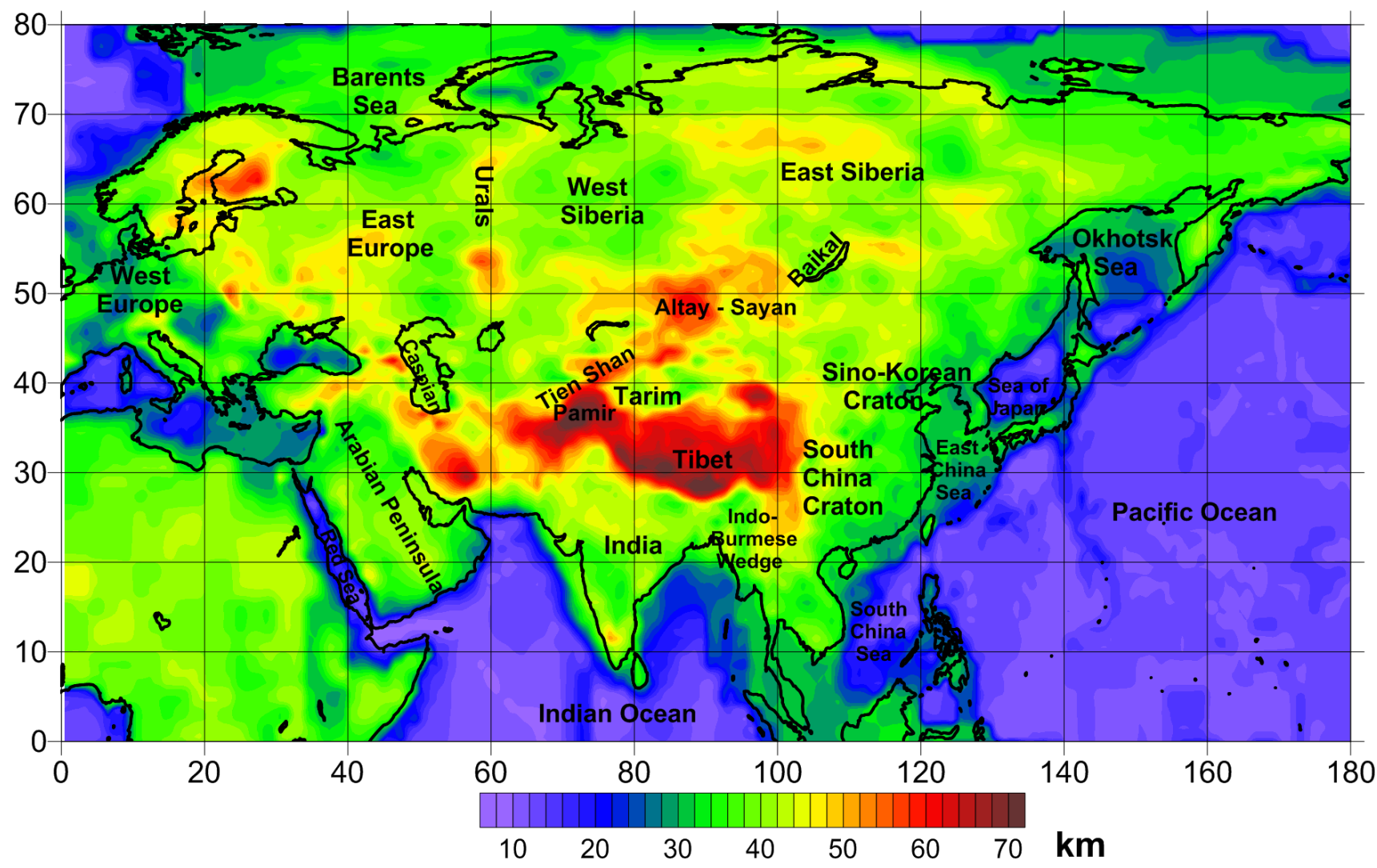

Figure 2. Depth to the Moho from sea level.

Moho depths demonstrate less variation than the original data, which reduces the interpolation uncertainty by $30 \%$ or more [Stolk et al., 2013. After the interpolation of residual values, the initial correction, which was applied to the point data, is restored, leading to the final Moho map. Within this procedure, it became possible to outline principal features like mountain ranges, which were investigated by seismic methods only in a few points. It is important to note that this technique helps to interpolate heterogeneous datasets but not to substitute them. Therefore, reliability of the results in each specific area depends on the available seismic determinations. The final map of the Moho depth is shown in Figure 2.

\section{Residual Gravity Anomalies and Residual Topography}

To refine the effect of the upper mantle, the gravity effect of the crustal layers has been estimated relative to a 1D reference density model. Therefore, the crustal correction is similar to the Bouguer correction extended from the surface to the Moho [Kaban et al., 2016a, Mooney and Kaban, 2010. Any plausible changes of the reference model chiefly lead to a constant shift of the computed gravity field, which is not important since we consider only variations of the gravity field relative to the average level (anomalies). In this study the same reference model (Table 1) is used as in pre-

Table 1. 1D Reference Density Model Used for the Calculation of the Crustal Effect

$$
\text { Upper layer } \quad \text { Lower crustal layer } \quad \text { Upper mantle layer }
$$

$\begin{array}{lccc}\text { Depth }(\mathrm{km}) & 0-15 & 15-40 & 40-75 \\ \text { Density }\left(\mathrm{kg} / \mathrm{m}^{3}\right) & 2700 & 2940 & 3357\end{array}$


vious regional [Kaban et al., 2010, 2014, Mooney and Kaban, 2010 and global studies [Kaban et al., 2003, 2014. This provides a possibility for direct comparison of the results obtained for different regions.

A calculation method implies a 3D algorithm for a spherical Earth, which takes into account both vertical and horizontal density variations and the elevation of topography in each point represented by volumes (tesseroids), which are bounded by specific latitudes and longitudes on the $1^{\circ} \times 1^{\circ}$ geographical grid in horizontal directions and by upper and lower boundaries of any specific layer vertically. More details about the computation technique can be found in [Kaban et al., 2016c. The maximum calculation error is less than $1 \mathrm{mGal}$, which is far below the impact of the initial data uncertainties.

The gravity effect of mass anomalies outside the study area could be remarkable [Kaban et al., 2003. 2016a. Even the differences between the Northern and Southern Hemispheres strongly influence all fields. To overcome this problem, we calculated all gravity effects for the whole Earth. This has been done by implementation of the high-resolution model of Eurasia in the global one provided by other studies e.g. [Laske et al., 2013]. The fields induced by the sediments, crystalline crust and Moho boundary are demonstrated in Figure 3 a Figure 3.

The gravity effect of the sedimentary layer varies within -110 to $0 \mathrm{mGal}$ (Figure $3 \mathrm{a})$. The minimal anomalies correspond to the basins, which are characterized by young low-density sediments (like offshore basins), or to the continental basins with low-density sediments including salt deposits (e.g. the Pre-Caspian basin). Both in the oceanic and continental areas, this effect is controlled not only by thickness but also by the type of basins, which might be characterized by different density-depth relationships [Kaban et al., 2010, 2016a, Stolk et al., 2013.

The gravity effect of the solid crust is even much higher than the effect of sediments and ranges from about -160 to $350 \mathrm{mGal}$ (Figure $3 \mathrm{~b}$ ). Besides the average density of the crust, it depends on the Moho depth and bottom of the sedimentary layer. If the last one reaches or exceeds $15 \mathrm{~km}$, the reference density is increased to $2940 \mathrm{~kg} / \mathrm{m}^{3}$ (Table 1), which significantly modifies the effect of the solid crust. This is the case for South Caspian, Barents and Okhotsk Seas (Figure 3b) [Kaban et al., 2016a. However, the effect of the Moho undulations exceeds both of them (Figure $3 \mathrm{c}$ ), it varies from -260 to more than $800 \mathrm{mGal}$.

The effect of the crustal layers including the topography and bathymetry has been removed from the observed gravity field, which gives the residual anomalies showing the effect of density variations within the mantle. The aim of the reviewed studies was to investigate density structure of the upper mantle above the depth $325 \mathrm{~km}$. This depth was chosen as the maximum possible depth of the lithospheric roots e.g. [Kaban et al., 2003]. Therefore, it was necessary to remove also the effect of deeper layers. This has been done based on global models obtained in previous studies [Kaban et al., 2015, 2016a. The obtained residual mantle gravity anomalies are shown in Figure 4 .

As it was mentioned above, another important parameter, which is required to study the upper mantle structure, is the residual topography $-t_{r e s}$, - which represents the part of the observed topography that is not- or overcompensated by the crustal structure in an isostatic sense [Kaban et al., 2004. It is also calculated using the same crustal model based on seismic data Figure 1 and Figure 2) [Kaban et al., 2016a] (1):

$$
\begin{aligned}
& t_{\mathrm{res}}=\frac{1}{\bar{\rho}}\left(\rho_{\mathrm{top}}\right) t_{\mathrm{obs}}+ \\
& \frac{1}{\bar{\rho}} \int_{0}^{M} \Delta \rho(h)\left(\frac{R-h}{R}\right)^{2} d h
\end{aligned}
$$

where $\rho_{\text {top }}$ is the average block density of topography including the effect sediments $-t_{\mathrm{obs}} ; \bar{\rho}=$ $2670 \mathrm{~kg} / \mathrm{m}^{3}$ is the average density of $t_{\text {res }} ; \Delta \rho(h)$ is the density anomaly including water, relative to the horizontally homogeneous reference model; $t$ is the topography height, which is zero for sea areas; $h$ is the depth below the geoid; and $R$ is the radius of the Earth.

The effect of the deep mantle (dynamic topography) has been also removed from the calculated residual topography as it was done above for the residual mantle gravity anomalies [Kaban et al., 2016a. The dynamic topography was calculated based on existing global dynamic models of the mantle [Kaban et al., 2014 Petrunin et al., 2013. The last models take into account the effect of lateral viscosity variations including weak plate 

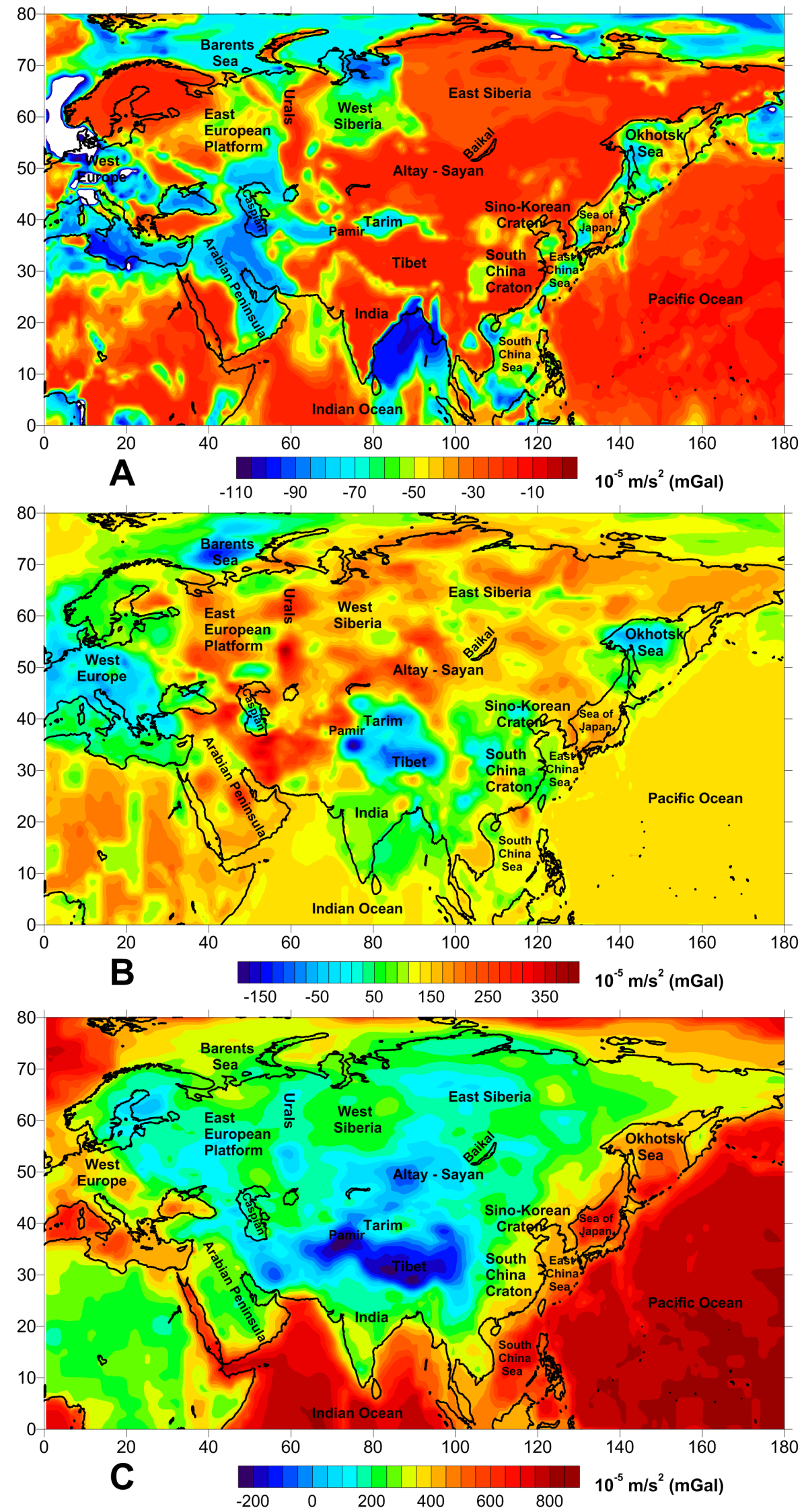

Figure 3. Gravity effect of different layers of the crust relative to the reference density model: (A) sediments; (B) crystalline crust; (C) Moho [Kaban et al., 2010, 2016a. 

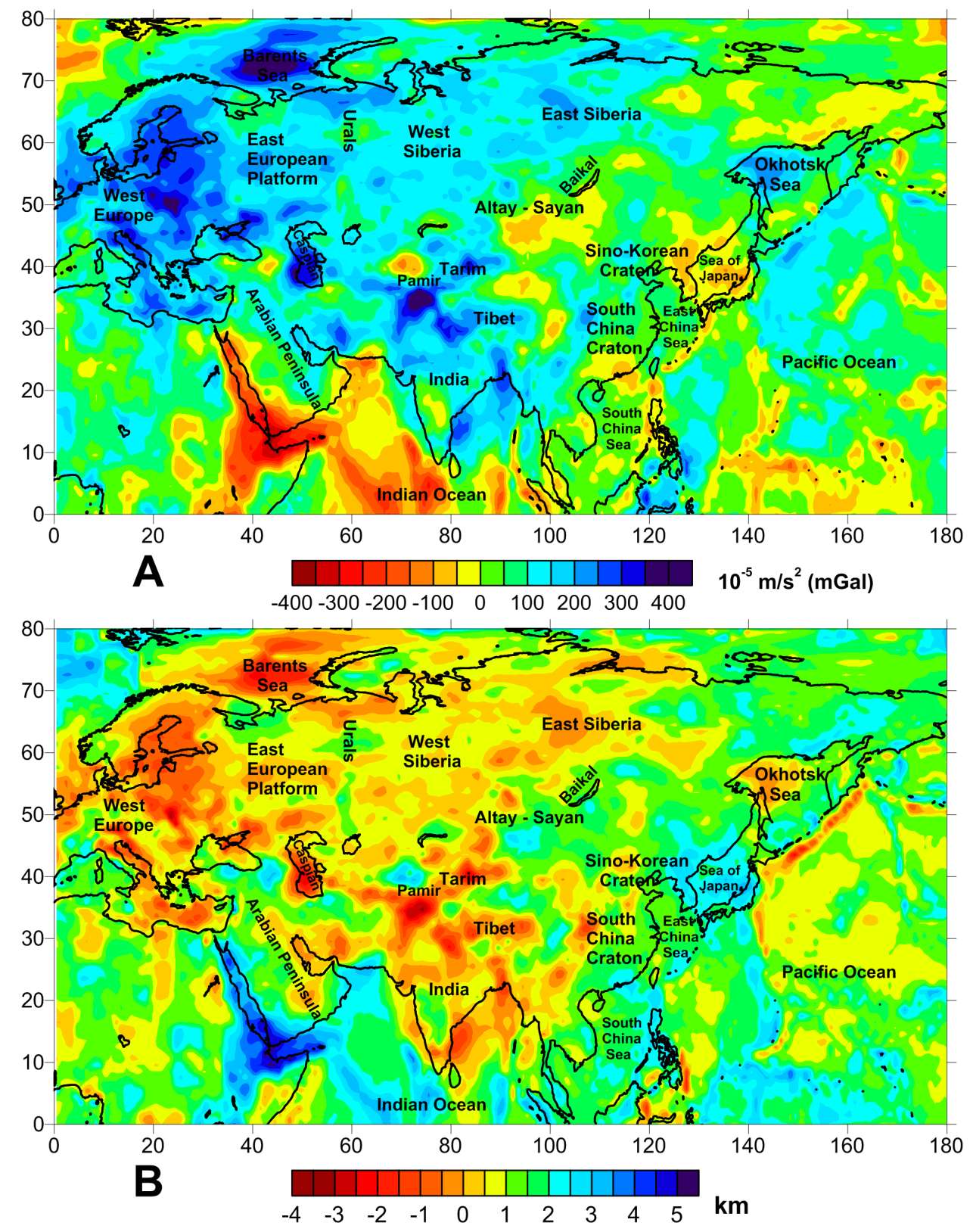

Figure 4. (A) Mantle gravity anomalies and (B) residual topography obtained by removing the crustal effects from the observed fields. The density of the residual topography is $2670 \mathrm{~kg} / \mathrm{m}^{3}$.

boundaries and the density variation related to the top and bottom of the mantle transition zone (410$660 \mathrm{~km}$ ) [Kaban and Trubitsyn, 2012]. The obtained residual topography is shown in Figure $4 \mathrm{~b}$.

The mantle gravity anomalies and residual topography vary within ranges of $\pm 400 \mathrm{mGal}$ and from $-4 \mathrm{~km}$ to more than $5 \mathrm{~km}$ correspondingly. Hence, the principal anomalies are significantly larger than potential uncertainties of these fields
[Kaban et al., 2016a]. As it is visible in Figure 4. the variations of these fields are opposite, since density anomalies in the upper mantle differently affect the gravity field and dynamic topography. It will be demonstrated further that using both fields in the inversion provides a possibility to obtain much more reliable 3D model of the mantle.

The largest negative mantle gravity anomalies (and positive topography) are found in areas af- 
fected by intensive mantle plumes, as the Afar triple junction (-480 mGal, Figure 4). Strong negative mantle gravity anomalies also characterize back-arc basins in East Asia (e.g. the Sea of Japan and the South China Sea) [Kaban et al., 2016a. In contrast, a significant positive mantle gravity anomaly $(>400 \mathrm{mGal})$ is found in the Barents Sea. Distinct common trends in the mantle gravity anomalies and residual topography can be formulated for the territory of Eurasia (Figure 4). Mostly negative residual gravity anomalies (and positive residual topography) are typical for Southeast Asia [Kaban et al., 2016a. In the northwestern part of the study area, the transition between predominantly positive and negative anomalies continues from Altay to the Baikal rift zone and then to the north dividing the Siberian Craton and West Siberian Basin (Figure 4). A very pronounced maximum of the residual mantle gravity anomalies and a corresponding minimum in the residual topography are found in the South Caspian basin [Kaban et al., 2016a, 2016b]. Strong positive mantle gravity anomalies are typical for the boundary of the Himalayas and Tibetan plateau as well as for the southern Pamir Mountains. These anomalies are likely related to the continental plate collision and subduction. One can specify two types of the old continental cratons, which are characterized by different patterns of the calculated anomalies. Significant maxima of the residual mantle anomalies (and minima of the residual topography) are typical for the Siberian and East European, while the Indian, South China, and Sino-Korean cratons are characterized by near zero or even negative residual mantle gravity anomalies.

\section{Initial Density Model of the Upper Mantle Based on Seismic Tomography}

To determine initial density variations in the upper mantle, which are used as a priory constraint in the inversion, S-wave velocity variations from the SL2013sv tomography model [Schaeffer and Lebedev, 2013, 2014 have been converted to temperature and then to density variations [Kaban et al., 2016a. For this conversion, the method based on mineral physics equations has been employed [ $\mathrm{Ka}$ ban et al., 2014, 2016b, Tesauro et al., 2014. The temperature and density variations have been com- puted for the upper mantle down to the depth $325 \mathrm{~km}$ using the method of Stixrude and LithgowBertelloni 2005. The composition of the mantle material corresponds to the Primitive Mantle and implies $58.5 \%$ olivine, $11.5 \%$ clinopyroxene (CPX), $15.0 \%$ orthopyroxene (OPX), and $15.0 \%$ garnet [McDonough and Sun, 1995]. For the anelastic correction, the attenuation model Q4 was employed following Cammarano et al. 2003. The calculated density variations at the depths 100, 150, and $200 \mathrm{~km}$ are shown in Figure 5.

\section{Final 3D Density Model of the Upper Mantle of Eurasia}

The computed residual mantle gravity anomalies and residual topography together with the initial density model of the upper mantle based on seismic tomography open possibilities for modelling a 3D density structure of the upper mantle. Both mantle gravity anomalies and residual topography depend on density variations in the upper mantle but the relationships between the amplitude of the anomalies, size and depth are principally different [Kaban et al., 2015]. Consequently, inversion of both parameters improves resolution of the constructed 3D density model. The objective function for the inversion is as follows [Kaban et al., 2016a] (2):

$$
\begin{gathered}
\min \left\{\left\|A \rho-g_{\text {res }}\right\|^{2}+k\left\|B \rho-t_{\text {res }}\right\|^{2}+\right. \\
\left.\alpha\left\|\rho-\rho_{\text {ini }}\right\|^{2}\right\}
\end{gathered}
$$

where $A \rho$ is the integral operator converting density variations in the gravity field, $B$ is the integral operator converting density in topography perturbations, $\alpha$ is the damping factor used to stabilize the solution, and $k=2 \pi G \rho_{t}$ is the scaling coefficient normalizing topography and gravity. The regularization condition implies that the obtained density structure should be close to a predefined model. If such a model is not available $\left(\rho_{\text {ini }}=0\right)$, the obtained density perturbations should be minimal, therefore, this is an Occam-type inversion. The solution was found in a spherical harmonic domain, where this can be done for each set of spherical coefficients (for specific degree/order) separately e.g. [Forte and Peltier, 1991]. The integral operator $B$ employed for the calculations of 

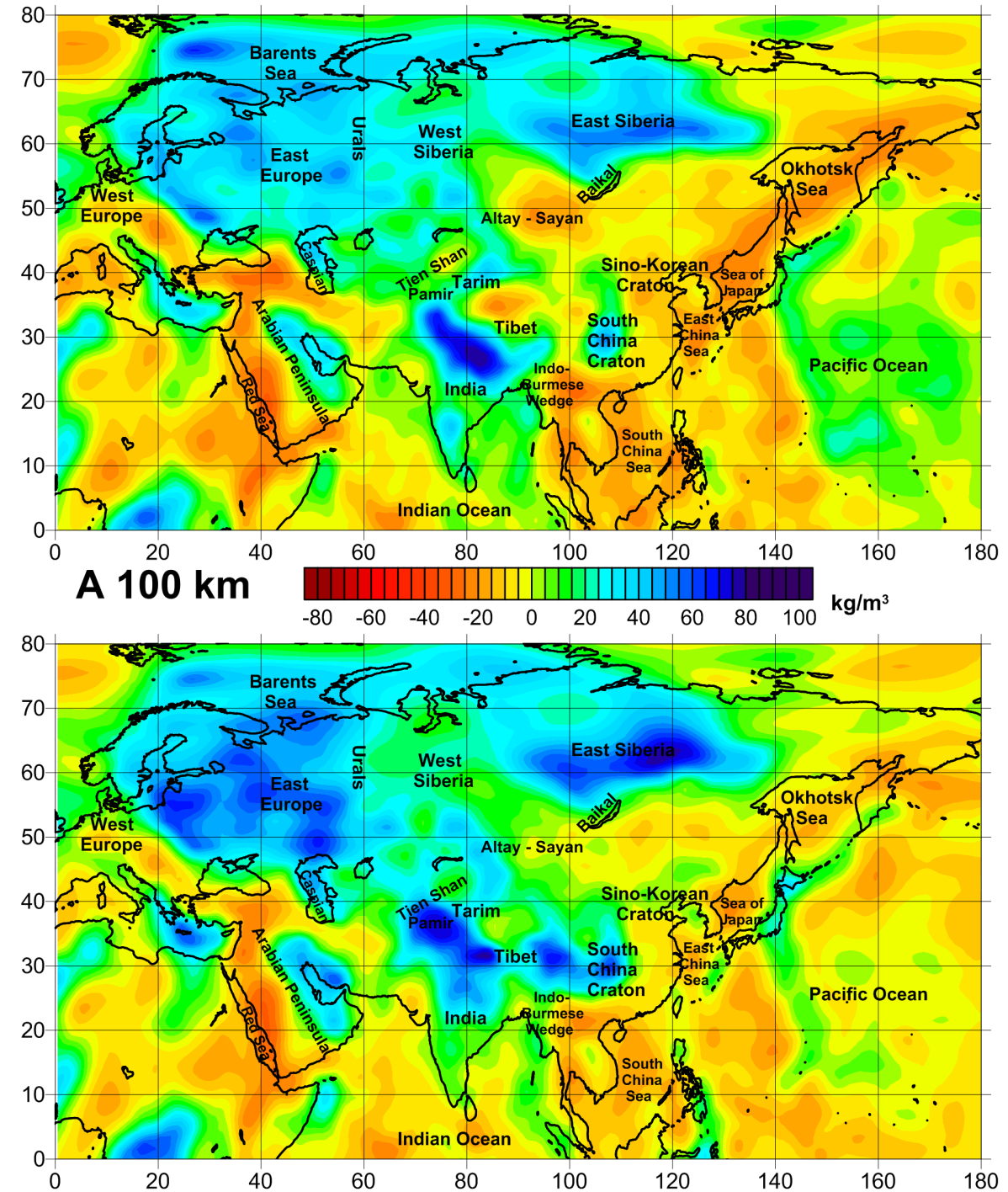

B 150 km
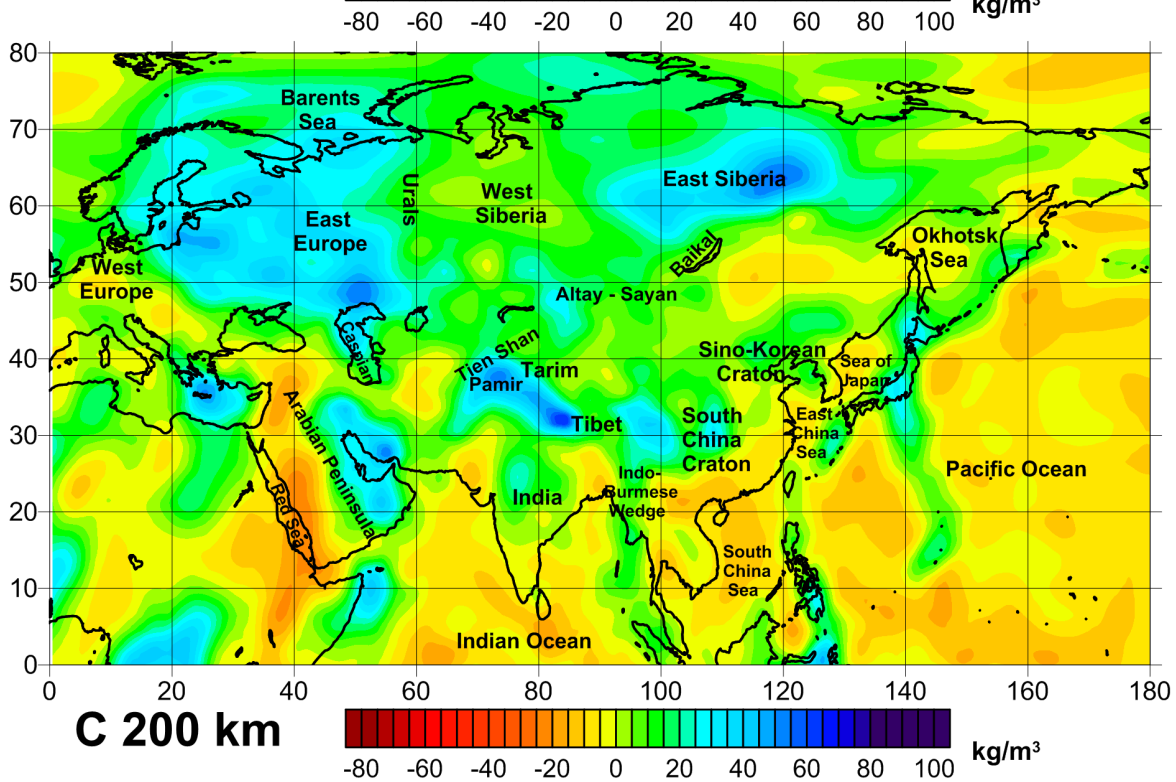

Figure 5. Initial density model of the uppermost mantle. Density variations are shown at depths of (A) $100 \mathrm{~km}$, (B) $150 \mathrm{~km}$, and (C) $200 \mathrm{~km}$. 
dynamic topography perturbations depends on the viscosity model of the mantle, which is based on previous investigations [Kaban et al., 2015.

The obtained final density variations in the uppermost mantle are shown in Figure 6 for 3 depths $(100,150$ and $200 \mathrm{~km})$ [Kaban et al., 2016a]. The inverted model corresponds well to both fields (the gravity anomalies and residual topography). The difference of the computed gravity filed from the initial one is within -19 to $14 \mathrm{mGal}$, root mean square $(\mathrm{rms})=2.4 \mathrm{mGal}$, which is much less than variations of the mantle gravity anomalies Figure 4 a). Differences of the computed and residual topography are in the same proportion: from $-0.09 \mathrm{~km}$ to $0.07 \mathrm{~km}, \mathrm{rms}=0.014 \mathrm{~km}$. However, the calculated corrections to the initial density model (Figure 5) are remarkable $\left( \pm 50 \mathrm{~kg} / \mathrm{m}^{3}\right)$. Even these values represent a lower limit of possible density variations due to the damping of the third regularization term in (2).

One of the main results of the inversion is enhanced resolution, especially for horizontal density variations (Figure 6). However, some local anomalies in the uppermost mantle (Figure 6a) could be a result of possible uncertainties of the crustal model. These uncertainties lead to artificial anomalies, which can be propagated from the crust to the uppermost mantle due to the damping (2). This is likely the case for the small-scale anomalies with the Siberian and East European cratons at the depth $100 \mathrm{~km}$ [Kaban et al., 2016a. These cratons are also characterized by the largest negative correction of density at the depth $150 \mathrm{~km}$, which persists down to a depth of $250 \mathrm{~km}$ Figure $6 \mathrm{a}$ to Figure $6 \mathrm{p}$ ). These corrections evidence for the depleted mantle material that exists since formation of these old tectonic units e.g. [Jordan, 1978, 1988. As it was already mentioned, the depleted mantle is less dense than the primitive one at the same P-T conditions. The initial models for both cratons are well-constrained by seismic data, therefore these results are robust. The minimum density correction reaches $-50 \mathrm{~kg} / \mathrm{m}^{3}$ in the Lower Lena basin, Anabar shield and Viluy basin (Figure 6 a to Figure 6.).

The obtained results provide a possibility for testing of the isopycnic hypothesis of Jordan 1978 . 1988, according to which the thermal and composition induced density anomalies in the cratonic upper mantle compensate each other giving a near zero anomaly. The reviewed studies demonstrate that this assumption is not completely valid for both the East European and Siberian cratons. In these structures the total density anomaly remains positive (about $40 \mathrm{~kg} / \mathrm{m}^{3}$ ) at the depths $100-200 \mathrm{~km}$ (Figure $6 \mathrm{~d}$ to Figure $6 \mathrm{f}$ ), which indicates that the effect of low temperatures in the upper mantle still exceeds the opposite effect of depletion [Kaban et al., 2016a.

For some cratons in South Asia, such as for the Indian Craton, the correction to the initial model is also negative, which clearly indicates the presence of the depleted material, especially at the depth $100 \mathrm{~km}$ (Figure 6a). However, other cratons, such as the Sino-Korean and South China ones, don't demonstrate this tendency and the correction of the mantle density obtained for them is insignificant. This could be evidence that the old cratonic roots have been reworked and the depleted material has been replaced by the primitive mantle. Before, this was suggested based on indirect petrological and geological data [Kusky et al., 2007, Yang et al., 2010; Zheng and Zhang, 2007. In the reviewed papers, the recent changes of the Sino-Korean and South China cratonic roots are demonstrated directly by construction the integrative $3 \mathrm{D}$ model of the upper mantle [Kaban et al., 2016a.

For most of the active mountain belts (e.g. for the Zagros and Himalayas fold belts and Tibet) the final model demonstrates much more details compared to the initial one but doesn't suggest principal changes. This evidences that the density structure of the upper mantle is chiefly controlled by temperature variations, which are well exposed in seismic velocity variations. The same conclusion can be made for the Trans-Baikal and Altay-Sayan mountain regions [Kaban et al., 2016a]. In contrast, the tomography model doesn't resolve structure of the Indo-Burmese wedge due to low resolution. However, the evidence of continental subduction in this region is clearly visible in the inverted model (Figure $6 \mathrm{~d}$ to Figure $6 \mathrm{f}$ ).

For the Pamir and Tien Shan mountain region, the obtained density model is different from the described above. The negative density anomalies are recognized only in the uppermost mantle at about $100 \mathrm{~km}$ (Figure 6) north of the boundary depicting the transition of the continental subduction from the southward direction under Pamir to the northward subduction under the Central Tien Shan [Fan 

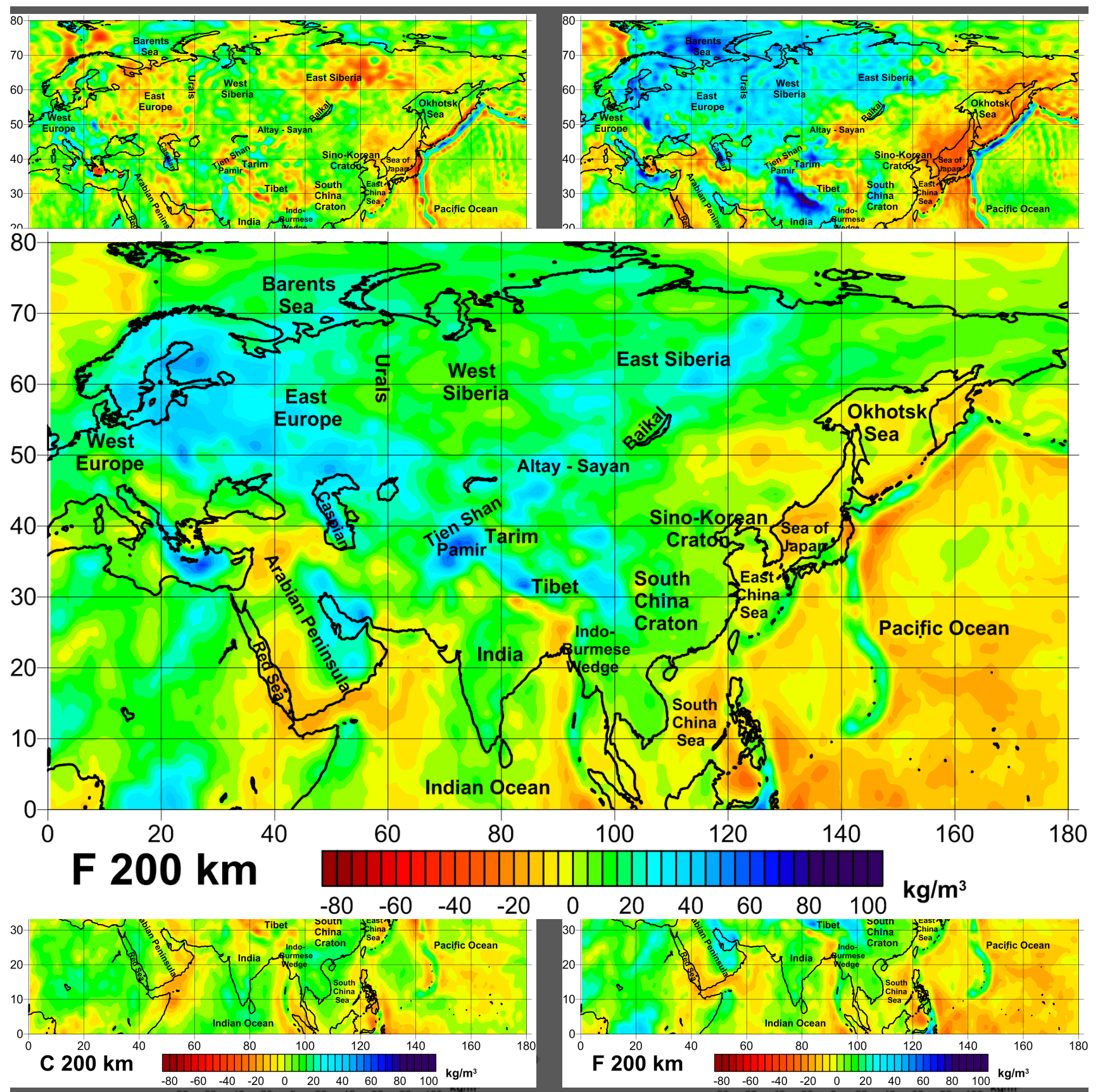

Figure 6. Density variations in the upper mantle at depths of 100, 150, and $200 \mathrm{~km}$ according to the constructed 3D density model. $\mathbf{A}, \mathbf{B}$, and $\mathbf{C}$ represent calculated corrections to the initial model in Figure 5, D, E, and $\mathbf{F}$ - final model obtained in the inversion. Editorial note: To zoom selected image click on the corresponding capital letter in red square, make one more click to return back.

et al., 1994. For the continuation of the negative anomaly to the north, it is still unclear whether it shows some principal changes in composition of the upper mantle or just improves resolution of the initial density model [Kaban et al., 2016a].

The obtained 3D density model is principally improved for the Arabian plate and surrounding areas [Kaban et al., 2016b]. The Arabian platform 
and Arabian shield demonstrate principally different density patterns of the lithosphere. Density of the uppermost mantle in the Arabian shield is normal, while it is underlain by relatively low-dense material below the depth $100 \mathrm{~km}$ (Figure 6). This low-density anomaly continues under the central part of the Red Sea, which is likely appeared after extension of the Red Sea rift e.g. [Chang and Van der Lee, 2011. Opposite to this anomaly, the subcrustal layer in the Arabian platform is relatively low-dense, while below we identify a high-density anomaly extending to the depth $200 \mathrm{~km}$ (Figure 6) [Kaban et al., 2016b]. The Red Sea rift is divided into 3 parts: the tectonics of the South Red Sea is obviously controlled by the Afar plume with the negative anomaly, which is observed through the entire upper mantle. The North Red Sea represents a passive extension pattern with the negative density anomaly concentrated under the crust above $100 \mathrm{~km}$ (Figure 6). The Central Red Sea likely represents a transition between these two regimes.

Several high-density zones are found in the upper mantle below the Tarim and South Caspian basins, the Barents and Okhotsk seas as well as under the Bay of Bengal (Figure 6). A significant part of these positive anomalies has appeared after the inversion with the mantle gravity field and residual topography. We attribute these anomalies to the presence of the eclogite materials previously reported for the Gulf of Mexico [Mooney and Kaban, 2010 and for the Barents Sea [Braitenberg and Ebbing, 2009]. As was mentioned above, the density of eclogites significantly exceeds the standard peridotite density, while the seismic velocities characterizing these rocks are nearly the same $[\mathrm{Ka}$ ban et al., 2016a, 2016b. Therefore, these studies demonstrate that an integrative analysis of several fields can provide much more information than only one method such as seismic tomography. These studies confirm that the gabbro-eclogite transformation is a key for development of many sedimentary basins causing their quick subsidence [Kaban et al., 2016a.

\section{Modelling Results Discussion}

The modelling results can be formulated as follows [Kaban et al., 2010, 2016a; 2016b:

1. It has been created an integrative density model of the crust and upper mantle for Eurasia and surrounding areas. At the first stage, the variations of the residual gravity and residual topography have been estimated, which vary from -400 to $400 \times 10^{-5} \mathrm{mGal}$ and from $-4 \mathrm{~km}$ to $5 \mathrm{~km}$ correspondingly. These fields uncover density variations in the upper mantle and can be employed in various studies.

2. A 3D density model of the mantle has been obtained from the inversion of the residual topography and residual mantle gravity anomalies. The inversion was additionally constrained by the initial density model based on the recent seismic tomography model [Schaeffer and Lebedev, 2013. The perturbations to the initial model vary within $-50 \mathrm{~kg} / \mathrm{m}^{3}$ to $50 \mathrm{~kg} / \mathrm{m}^{3}$. In the inversion, the resolution of the initial model has been greatly improved, which revealed several main features of the upper mantle that were not sufficiently resolved by seismic tomography.

3. The most significant negative density corrections are obtained for the East European and Siberian cratons. These anomalies can be related to the depleted mantle material. The maximum amplitude of the density depletion is $45 \mathrm{~kg} / \mathrm{m}^{3}$ at the depth $100 \mathrm{~km}$. Nevertheless, the density decrease doesn't fully compensate the effect of low temperatures. The increased density (up to $40 \mathrm{~kg} / \mathrm{m}^{3}$ ) is still observed at the depths $100-170 \mathrm{~km}$. Therefore, the isopycnic hypothesis of Jordan, 1988 is not completely accomplished.

4. The density structure of the South China and Sino-Korean cratons is different from the northern cratons. It is characterized by slightly negative anomalies down to a depth of about $100 \mathrm{~km}$. Thus, the original depleted material, formed these old cratonic roots, has been replaced by the primitive mantle.

5. In Southern and Central Eurasia, significant corrections to the initial model are not discovered. Consequently, the tomography model sufficiently describes these structures, and most of the density changes can be related with temperature variations. The Indo-Burmese wedge represents an exception, 
where the joint interpretation of several datasets uncovers the structure related to intracontinental subduction.

6. The Arabian plate consists of two different parts characterized by different density variations in the upper mantle. The Arabian shield is characterized by low-dense and likely hot upper mantle $100 \mathrm{~km}$. To the west, this lowdensity zone continues to the hot reservoir under the Red Sea. Differently, under the Arabian platform, the normal lithosphere persists to a depth of at least $200 \mathrm{~km}$.

7. The largest high-density anomalies in the upper mantle were found beneath several sedimentary basins, such as the South Caspian, Okhotsk and Barents seas, the Tarim basin as well as beneath the Bay of Bengal. These anomalies were not resolved in the seismic tomography model but appear in the inversion of the mantle gravity anomalies and residual topography. These results can be explained by the eclogites presented in the subcrustal layer, which are likely responsible for the quick subsidence of these basins.

\section{Data Representation}

The initial gridded data on the presented model were converted into the georeferenced raster format and processed and compiled as digital maps with a color ramp. All the data layers were provided with convenient network access using the Open Geospatial Consortium (http://www.opengeospatial.org/ accessed 23 April 2019) standard data exchange protocols (e.g. KML, WMS, WFS, etc.). For this, the prepared data layers were combined into map-services (mapping services) published in the web. All the digital maps were accompanied by metadata giving a brief description of the initial datasets, map compilation procedures and references.

The system that provides web-access and interaction with published spatial data includes several segments: the database server (DB-server), the GIS-server, and the web-server. The DB-server hosts the file storage and relational database managed by DB management system (DBMS). The spatial data (raster or vector) are stored in the file storage or DBMS-controlled database and presented as single or multilayer digital maps and published on the GIS-server as map services accessible via the web.

The main tool for interacting with the published map-services is the client application implemented as a geoportal and hosted on the web-server. It provides the user with a hierarchical catalogue of available map-services and digital maps as well as a set of tools for their analysis. The interaction between the servers is performed within the secured local network.

This approach allows to organize external network access to spatial data using standard protocols for exchange of geospatial information, without the need to directly copy the data locally. In this case the published map-services are accessible using both, stand-alone desktop GIS-suites and web-based interactive GIS. A series of geoportals devoted to the Earth sciences in general (http://gis.gcras.ru/) or to specific thematic areas, such as geology (http://geology-gis.gcras.ru/) or seismology (http://seismgis.gcras.ru/), were developed in the Geophysical Center of RAS. These geoportals are based on the unified approach and are hosted within the same server infrastructure, making them easily deployable and scalable [Krasnoperov et al., 2016, Nikolov et al., 2015. Soloviev et al., 2018.

\section{Conclusion}

The modern geoscience community draws attention to the continuous expansion and development of geophysical monitoring networks along with development and implementation of automated equipment that allows registration of various physical parameters with high frequency. Within the past two decades a series of specialized geophysical satellite missions has been successfully launched (Swarm, CHAMP, GOCE, GRACE etc.). These missions provided global coverage with highly-accurate geophysical measurements. All these factors cause a significant increase in the volume of geophysical data. This allows to refer the data of geophysical monitoring to the so-called "Big Data". Currently, the concept of Big Data is interpreted as four Vs: volume, variety, velocity and veracity [Rybkina et al., 2018 Science International, 2015.

In this regard, the approaches, presented in this paper, fully comply with this concept. Storage of 
geophysical data in the form of GIS-compatible data-layers with subsequent publication as mapservices allows to organize free access, using a wide range of standard interaction options. The advantage of this approach is that the data is stored, distributed, and accessed through standard protocols or by means of web-geoportals. This approach to the storage of spatial geophysical data corresponds to another concept that is currently being developed - FAIR. According to this concept, all the scientific data should be easy to find (Findable), access should be provided to them (Accessible), convenient interaction with the data should be ensured (Interoperable), the possibility of data reuse should be provided (Re-usable) [Wilkinson et al., 2016. The series of geoportals mentioned in the paper provide effective instruments for representation and analysis of large arrays of spatial data on a large group of thematic areas.

Acknowledgments. This work was conducted in the framework of budgetary funding of the Geophysical Center of RAS, adopted by the Ministry of Science and Higher Education of the Russian Federation. This work employed services and data provided by the Shared Research Facility "Analytical Geomagnetic Data Center" of the Geophysical Center of RAS (http://ckp.gcras.ru/).

\section{References}

Anderson, D. L., J. D. Bass (1984), Mineralogy and composition of the upper mantle, Geophysical Research Letters, 11, 637-640, Crossref

Beriozko, A., A. Lebedev, A. Soloviev, et al. (2011) Intellectual Geoinformation System for Earth Sciences, Environment Technology Resources Proceedings of the International Scientific and Practical Conference, 2, 48, Crossref

Beriozko, A., et al. (2009), Intellectual GIS, Herald of the Earth Sciences Department of RAS, 1, 1-7, Crossref

Braitenberg, C., J. Ebbing (2009), The GRACEsatellite gravity and geoid fields in analysing largescale, cratonic or intracratonic basins, Geophysical Prospecting, 57, 559-571, Crossref

Cammarano, F., et al. (2003), Inferring uppermantle temperatures from seismic velocities, Physics of the Earth and Planetary Interiors, 138, Crossref

Chang, S.-J., S. Van der Lee (2011), Mantle plumes and associated flow beneath Arabia and East Africa, Earth and Planetary Science Letters, 302, 448-454, Crossref
Christensen, N. I., W. D. Mooney (1995), Seismic velocity structure and composition of the continental crust: A global view, Journal of Geophysical Research: Solid Earth, 100, 9761-9788, Crossref

Divins D. L. (2003), Total Sediment Thickness of the World's Oceans and Marginal Seas, NOAA NGDC, Boulder, Colorado.

Exxon (1985), Tectonic Map of the World, 16 pp. Tulsa, Okla.

Fan, G., et al. (1994), Active tectonics of the Pamirs and Karakorum, Journal of Geophysical Research, 99, 7131, Crossref

Forsberg, R., C. C. Tscherning (1997), Topographic effects in gravity field modelling for BVP, Geodetic Boundary Value Problems in View of the One Centimeter Geoid p. 239-272, Springer-Verlag, Berlin.

Forte, A. M., R. Peltier (1991), Viscous flow models of global geophysical observables: 1. Forward problems, Journal of Geophysical Research: Solid Earth, 96, 20,131-20,159, Crossref

Fu, P. (2016), Getting to Know Web GIS, ESRI Press, Redlands, CA, USA.

Goes, S., R. Govers, P. Vacher (2000), Shallow mantle temperatures under Europe from $\mathrm{P}$ and $\mathrm{S}$ wave tomography, Journal of Geophysical Research: Solid Earth, 105, Crossref

Jordan, T. H. (1978), Composition and development of the continental tectosphere, Nature, 274 , No. 5671, 544-548.

Jordan, T. H. (1988), Structure and formation of the continental tectosphere, J. Petrol., 1, Special Volume, 11-37, Crossref

Kaban, M. K. (2011), Gravity anomalies, Interpretation, Encyclopedia of Solid Earth Geophysics (2nd Edition), Gupta H. K. (ed.) p. 456-461, Springer, Dordrecht. (ISBN 978-90-481-8701-0)

Kaban, M. K., et al. (2016a), 3D density model of the upper mantle of Asia based on inversion of gravity and seismic tomography data, Geochemistry, Geophysics, Geosystems, 17, 4457-4477, Crossref

Kaban, M. K., S. El Khrepy, et al. (2016b), Three-dimensional density model of the upper mantle in the Middle East: Interaction of diverse tectonic processes, Journal of Geophysical Research: Solid Earth, 121, Crossref

Kaban, M. K., S. El Khrepy, N. Al-Arifi (2016c), Isostatic Model and Isostatic Gravity Anomalies of the Arabian Plate and Surroundings, Pure and Applied Geophysics, 173, 1211-1221, Crossref

Kaban, M. K., W. D. Mooney, A. G. Petrunin (2015), Cratonic root beneath North America shifted by basal drag from the convecting mantle, Nature Geoscience, 8, 797-800, Crossref

Kaban, M. K., A. G. Petrunin, H. Schmeling, M. Shahraki (2014), Effect of Decoupling of Lithospheric Plates on the Observed Geoid, Surveys in Geophysics, 35, 1361-1373, Crossref

Kaban, M. K. , P. Schwintzer, I. M. Artemieva, W. D. Mooney (2003), Density of the continen- 
tal roots: compositional and thermal contributions, Earth and Planetary Science Letters, 209, 53-69, Crossref

Kaban, M. K., P. Schwintzer, C. Reigber (2004), A new isostatic model of the lithosphere and gravity field, Journal of Geodesy, 78, 368-385, Crossref

Kaban, M. K., M. Tesauro, S. Cloetingh (2010), An integrated gravity model for Europe's crust and upper mantle, Earth and Planetary Science Letters, 296, 195-209, Crossref

Kaban, M. K., V. Trubitsyn (2012), Density structure of the mantle transition zone and the dynamic geoid, Journal of Geodynamics, 59-60, 183-192, Crossref

Krasnoperov, R. I., A. A. Soloviev (2015), Analytical geoinformation system for integrated geologicalgeophysical research in the territory of Russia, Mining Journal (Gornyi Zhurnal), 10, 89-93, Crossref

Krasnoperov, R. I., A. A. Soloviev, B. P. Nikolov, et al. (2016), Interactive web-application for complex studying of spatial information on Earth sciences from the geodatabase of GC RAS, Geoinformatics Research Papers, 4, Crossref

Kusky, T. M., B. F. Windley, M.-G. Zhai (2007), Tectonic evolution of the North China Block: from orogen to craton to orogen, Geological Society, London, Special Publications, 280, 1-34, Crossref

Laske G. et al. (2013), Update on CRUST1.0-a 1-degree global model of Earth's crust. Geophys. Res. Abstr. EGU General Assembly 2013, 7-12 April, 2013 in Vienna, Austria

McDonough, W. F., S. S. Sun (1995), The composition of the Earth, Chemical Geology, 120, 223-253, Crossref

Mooney, W. (2007), Crust and Lithospheric Structure - Global Crustal Structure, Volume 1: Seismology and the Structure of the Earth p. 361-417, Elsevier, Crossref

Mooney, W. D., M. K. Kaban (2010), The North American upper mantle: Density, composition, and evolution, Journal of Geophysical Research, 115, Crossref

Nikolov, B. P., J. I. Zharkikh, A. A. Soloviev, et al. (2015), Integration of data mining methods for Earth science data analysis in GIS environment, Russian Journal of Earth Sciences, 15, 1-14, Crossref

Petrunin, A. G., M. K. Kaban, I. Rogozhina, V. Trubitsyn (2013), Revising the spectral method as applied to modeling mantle dynamics, Geochemistry, Geophysics, Geosystems, 14, 3691-3702, Crossref

Rybkina, A., S. Hodson, A. Gvishiani, et al. (2018), CODATA and global challenges in data-driven science, Russian Journal of Earth Sciences, 18, 1-11, Crossref

Schaeffer, A. J., S. Lebedev (2013), Global shear speed structure of the upper mantle and transition zone, Geophysical Journal International, 194, 417449, Crossref

Schaeffer, A. J., S. Lebedev (2014), Imaging the North American continent using waveform inversion of global and USArray data, Earth and Planetary Science Letters, 402, 26-41, Crossref

Open Data in a Big Data World. Paris: International Council for Science (ICSU), International Social Science Council (ISSC), The World Academy of Sciences (TWAS), InterAcademy Partnership (IAP)

Shako, R., C. Förste, O. Abrikosov, et al. (2013), EIGEN-6C: A High-Resolution Global Gravity Combination Model Including GOCE Data, Advanced Technologies in Earth Sci. p. 155-161, Springer, Berlin Heidelberg. Crossref

Soloviev, A. A., R. I. Krasnoperov, B. P. Nikolov, et al. (2018), Web-Oriented Software System for Analysis of Spatial Geophysical Data Using Geoinformatics Methods, Izvestiya, Atmospheric and Oceanic Physics, 54, 1312-1319, Crossref

Soloviev, A. A., J. I. Zharkikh, R. I. Krasnoperov, et al. (2016), GIS-oriented solutions for advanced clustering analysis of geoscience data using ArcGIS platform, Russian Journal of Earth Sciences, 16, 16, Crossref

Stixrude, L., C. Lithgow-Bertelloni (2005), Thermodynamics of mantle minerals - I. Physical properties, Geophysical Journal International, 162, 610-632, Crossref

Stolk, W., M. Kaban, F. Beekman, et al. (2013), High resolution regional crustal models from irregularly distributed data: Application to Asia and adjacent areas, Tectonophysics, 602, 55-68, Crossref

Tesauro, M., M. K. Kaban, S. A. P. L. Cloetingh (2008), EuCRUST-07: A new reference model for the European crust, Geophysical Research Letters, 35, Crossref

Tesauro, M., M. K. Kaban, S. A. P. L. Cloetingh (2009), 3D Crustal Model of Western and Central Europe as a Basis for Modelling Mantle Structure, New Frontiers in Integrated Solid Earth Sciences p. 39-69, Springer, Netherlands. Crossref

Tesauro, M., M. K. Kaban, et al. (2014), NACr14: A 3D model for the crustal structure of the North American Continent, Tectonophysics, 631, 65-86, Crossref

Wilkinson, M., M. Dumontier, I. Aalbersberg, et al. (2016), The FAIR Guiding Principles for scientific data management and stewardship, Scientific Data, 3160018, Crossref

Yang, J.-H., et al. (2010), Diachronous decratonization of the Sino-Korean craton: Geochemistry of mantle xenoliths from North Korea, Geology, 38, 799-802, Crossref

Zheng, Y., S. Zhang (2007), Formation and evolution of Precambrian continental crust in South China, Chinese Science Bulletin, 52, 1-12, Crossref

\section{Corresponding author:}

Roman I. Krasnoperov, Geophysical Center of RAS, 3 Molodezhnaya St., 119296 Moscow, Russia.

(r.krasnoperov@gcras.ru) 